\title{
Analyzing the Cross-National Comparability of Party Positions on the Social and EU Dimensions in Europe
}

November 29, 2018

\begin{abstract}
Using survey vignettes and scaling techniques, we estimate common socio-cultural and European integration dimensions for political parties across the member states of the European Union. Previous research shows that economic left/right travels well across the EU, meaning that the placements of parties on that dimension are crossnationally comparable; however, the social dimension is more complex, with different issues forming the core of the social dimension in different countries. The 2014 wave of the Chapel Hill Expert Survey includes anchoring vignettes which we use as "bridge votes" to place parties from different countries on a common social liberal/authoritarian dimension and a separate common scale for European integration. We estimate the dimensions using the Bayesian Aldrich-McKelvey technique. The resulting scales offer cross-nationally comparable interval-level measures of a party's social and EU ideological positions.
\end{abstract}


Expert surveys are an increasingly common tool for measuring latent concepts in the comparative social sciences (Norris, Frank, and Martínez i Coma 2014; Lindberg et al. 2014; Teorell, Dahlström, and Dahlberg 2011). One of the most prominent uses of expert surveys has been to obtain information on the policy positions of political parties in contemporary democracies (Benoit and Laver 2006; Hooghe et al. 2010; McElroy and Benoit 2010; Rohrschneider and Whitefield 2012; Bakker et al. 2015; Polk et al. 2017).

A central concern about the expert survey approach to estimating party positions pertains to the cross-national comparability of respondent placements (Budge 2000; McDonald, Mendes, and Kim 2007). If experts for each country place only the parties within a single party system, can we be sure that respondents for France conceive of and use a particular scale in the same way as their colleagues that complete a survey for the parties of Lithuania? At a time when party government faces representational challenges from both populism and technocratic management (Caramani 2017) and other analysts speak of a crisis of party democracy (Invernizzi-Accetti and Wolkenstein 2017), it becomes all the more pressing to understand the comparability of fundamental measures in widely used data on party politics.

Prior research combined 'blackbox' scaling techniques (Poole 1998) with a series of anchoring vignettes (King et al. 2004; King and Wand 2007) embedded within the 2010 Chapel Hill Expert Survey to show that expert placements of political parties on the economic leftright dimension are cross-nationally comparable across Europe (citation withheld). Yet, we also know that politics in many contemporary European democracies is multidimensional, and that a "second" dimension is an important determinant of public opinion and party competition on issues such as immigration and European integration (Hooghe and Marks 2009; Bornschier 2010; de Vries and Hobolt 2012; Kriesi et al. 2012; Rovny 2014; Häusermann and Kriesi 2015; Hobolt and de Vries 2015). As challenger parties that emphasize this cultural dimension become more prominent across the continent (Hobolt and Tilley 2016), we require a deeper understanding of the cross-national comparability of this more complex dimension 
in today's politics.

In addition to the social dimension, European integration has taken on increasing political importance, as the financial crisis and migration challenges have made clear (Bechtel, Hainmueller, and Margalit 2014; Copelovitch, Frieden, and Walter 2016). And although recent scholarship suggests that citizens perceive party shifts on European integration (Adams, Ezrow, and Somer-Topcu 2014), we still know less about the cross-national comparability of the European integration dimension. In short, while there is growing evidence that the left-right dimension "travels well" for expert survey respondents (citation withheld), it remains unclear if this is the case for other prominent dimensions of political competition in contemporary European societies.

We argue that this cross-national comparability of party positions on the prominent dimensions is of increasing importance for social scientists. A transnational model of European party competition is currently underdeveloped, but several features of European politics point in this direction. First, there is strong evidence that party policy diffuses across national borders, with parties learning from and adapting to successful strategies in neighboring countries (Böhmelt et al. 2016). Second, after the 2014 European Parliament (EP) elections, the Spitzenkandidat - "lead candidate" of the EP group - receiving the plurality of the vote was elected as the President of the European Commission (Schmitt, Hobolt, and Popa 2015). And although the effect of this new method of selecting the leader of the Commission may have been limited and somewhat polarizing, this form of transnational party competition will likely remain a feature of subsequent EP elections (Hobolt 2014; Popa, Rohrschneider, and Schmitt 2016). Third, the organization of EP groups and switching between groups is largely driven by questions of policy congruence between the national and transnational levels (McElroy and Benoit 2010). Finally, there is growing discussion of replacing the British seats in the European Parliament with a transnational list after the United Kingdom leaves the European Union, which would substantially advance forms of political competition that 
require additional information about the cross-national comparability of party positions.

This paper addresses questions of cross-national comparability for social left-right and European integration by combining anchoring vignettes embedded in the 2014 Chapel Hill Expert Survey (CHES) on party positions in Europe with Bayesian scaling techniques based on the

work of Aldrich and McKelvey (Aldrich and McKelvey 1977; Hare et al. 2015). Comparing the rank orderings of political parties in the raw and adjusted data, we demonstrate that, on the whole, there are few significant changes in ordering. This finding suggests that all three dimensions as measured by expert surveys are cross-nationally comparable. Using both the raw and rescaled measures, we replicate a prominent study on the relationship between economic left-right, social left-right, and party positions on European integration (Marks et al. 2006). We report that the central findings of that article hold when using either the raw or rescaled data from 12 years later, lending confidence to both those original findings and also the 2014 CHES data on party positions.

\section{CHES meets Bayesian Aldrich McKelvey}

The 2014 Chapel Hill Expert Survey on party positions in Europe is the most recent wave in an ongoing research project designed to measure the positions of political party leadership on dimensions and policies related to the economy, socio-cultural matters, and European integration (Hooghe et al. 2010; Bakker et al. 2015; Polk et al. 2017). 337 political scientists that study political parties and/or European integration completed the survey, and all 28 EU members, plus Norway, Switzerland, and Turkey, were included in the 2014 round. This produced information for a total of 268 political parties in Europe.

Each expert respondent placed the parties of only one party system, which creates some uncertainty as to whether or not the expert respondents use the various policy scales in comparable ways across countries. In order to address this concern, the survey included a 
series of anchoring vignettes (King et al. 2004; King and Wand 2007; citation withheld). This vignette section described the positions of three hypothetical parties for three dimensions: economic left-right, social left-right, and European integration. ${ }^{1}$ Unlike the majority of the survey, every CHES respondent had the opportunity to place these hypothetical parties on the same three scales, and these placements can then be used as bridging information to facilitate comparison of the respondents' other placements.

When survey respondents in different contexts answer the same survey questions, there is the potential that these respondents have different interpretations of the response categories. This is especially true when the response categories represent relative positions on a latent scale, such as left-right ideology. Differential-item functioning (DIF) occurs when the underlying scale is interpreted differently across a range of respondents. DIF can lead to a distortion of the placements of stimuli (i.e., political parties) on a given scale. For example, a British party expert and a Greek party expert may view the end points of a pro/anti EU integration scale in different ways, confounding the ability to compare parties' positions across countries.

In the late 1970s, Aldrich and McKelvey (1977) developed an estimation technique aimed at correcting DIF in perception/placement scales. Their solution, Aldrich-McKelvey scaling (henceforth A-M), assumes that there exists a true placement for a given stimuli (i.e. party) and that any individual placement of a stimuli is actually a linear distortion of this true placement. The A-M solution allows each survey respondent to have her own 'distortion' parameters, while treating the true placement of a stimuli as fixed across all respondents. The distortion parameters act in such a way as to allow different respondents to shift the true placement to the left or right and/or to expand or contract distances between placements on the underlying scale.

A-M takes advantage of the fact that survey respondents in their data all place the same set

\footnotetext{
${ }^{1}$ Online Appendix A provides the wording of the vignettes.
} 
of stimuli as well as placing themselves on an ideological left-right scale. This combination of information allows for estimation of the individual distortion parameters and results in a scale in which the placements of the respondents and stimuli are meaningfully comparable. We take advantage of this insight and employ a Bayesian version of this estimator to compare placements of political parties in different countries, where the placements are derived from country-specific respondents. As long as all of the respondents place at least one common stimuli, the solution to this problem is relatively straightforward.

As much of an innovation as A-M scaling represents in terms of overcoming problems with DIF, there are some serious limitations. Most notably for our purposes, A-M scaling does not allow for missing data when deriving a cross-contextually comparable scale. This is quite problematic as the CHES asks country-specific experts to place parties on a variety of dimensions, but only in the a single country. That is, British experts place only British parties and Greek experts place only Greek parties. When all of these country-specific data are combined, the resulting data matrix contains huge amounts of missing data, as British experts do not place Greek parties, etc. With this structure to our data, classic A-M scaling is not an option. A second limitation is that classic A-M scaling does not yield estimates of uncertainty for the estimated stimuli positions, which makes it impossible to discern whether or not two different candidates/parties are statistically distinguishable from one another on some dimension.

In order to overcome these limitations, we use the Bayesian Aldrich-McKelvey (BAM) scaling procedure developed in Hare et al. (2015). In that paper, the authors place senators, candidates for the Senate, and survey respondents on a common ideological scale. Their data are strikingly similar to ours in that only respondents from a senator's/candidate's state place that senator/candidate, which leads to an abundance of missingness in the final data set. The survey used by Hare et al. (2015) also asked respondents to place President Obama, the Democratic and Republican parties, and the Tea Party on the same ideological 
scale that they were placing their state-specific Senate candidates. So, while respondents in two different states placed different senators/candidates from one another, all respondents placed the president and the parties. These common stimuli act as 'bridging' votes and are the key to developing a cross-contextually comparable scale.

As described above, the 2014 wave of the CHES includes anchoring vignettes that we use as bridge votes to construct a cross-nationally comparable scale. The Bayesian implementation of A-M scaling easily handles the missing data in our model as missing values are automatically imputed via Markov chain Monte Carlo (MCMC). MCMC also directly produces measures of uncertainty that reflect both variance in the observed placements of parties as well as the degree of missingness for a given party. This yields larger standard errors for parties with fewer observed placements.

The BAM model closely resembles a Bayesian factor model, with the primary distinction being how the parameters and the latent variable are indexed. The factor model assumes that there is some latent variable, $X$, that is specific to a given respondent and that this latent variable is related to observable indicators through parameters (often called factor loadings) that are indexed by the observed indicators. In the BAM model, this indexing is reversed. This means that the the latent variable $X$ is indexed by the observable indicator and the parameters in the mode by respondent. For our data, this translates to the position of a party on a specific dimension $X_{j}$, where $j$ indexes party, being related to an expert's placement of that party $y_{i j}$, where $i$ indexes expert, through parameters $\alpha_{i}$ and $\beta_{i}$. Following the above discussion $\alpha$ and $\beta$ are the distortion parameters that map the expert's perception of a party's placement onto the 'true' position of that party.

To be Bayesian, we must specify distributional assumptions for the unknown quantities in the model. We must also specify the distribution of the dependent variables, in this case the expert placements of the parties, $y_{i j}$. As these placements are 11 point scales, we assume them to be normally distributed with an estimated mean and variance. We then set the 
mean position of expert $i$ 's placement of party $j$ to be equal to the the true position of party $j, X_{j}$, as well as the parameters $\alpha_{i}$ and $\beta_{i}$. Formally, the model is:

$$
\begin{aligned}
& y_{i j} \sim N\left(\mu_{i j}, \tau_{i j}\right) \\
& \mu_{i j}=\alpha_{i}+\beta_{i} X_{j}
\end{aligned}
$$

The unknown quantities, $\alpha, \beta$, and $X$ require prior distributions in the Bayesian setup. For this model, we specify uniform priors for $\alpha$ and $\beta$ and a standard Normal prior for $X$. Following Hare et al. (2015), we allow the variance of the expert placements to be a function of both expert and party, $\tau_{i}$ and $\tau_{j}$, with the total variance in $y_{i j}$ being the product of these 2 terms. Both the expert and the party variance terms are drawn from diffuse conjugate Gamma distributions. Formally:

$$
\begin{gathered}
\alpha_{i} \sim \text { Uniform }(-100,100) \\
\beta_{i} \sim \operatorname{Uniform}(0,100) \\
X_{j} \sim N(0,1) \\
\tau_{i j}=\tau_{i} \tau_{j} \\
\tau_{j} \sim \operatorname{Gamma}(1, .1) \\
\tau_{i} \sim \operatorname{Gamma}(\nu, \omega) \\
\nu \sim \operatorname{Gamma}(0.1,0.1) \\
\omega \sim \operatorname{Gamma}(0.1,0.1)
\end{gathered}
$$

In order to identify the model and to set the scale of the latent variable, we constrain the $\beta$ s to be positive. This assures that higher values of the latent variable, $X$, are associated with higher values of the expert placements. Substantively, this means for the economic and social left-right dimensions, higher values of the latent variable indicate more right-wing positions whereas for the EU dimension, higher values of the latent variable represent a more proEU position. As an additional identification constraint, we specified prior positions for the 
vignette party placements that respects the intended ordering of the vignette placements. This is what King et al. (2004) refer to as vignette equivalence and is a requirement of anchoring vignette-based scaling. That is, in order to be included in the model, experts must correctly perceive the ordering of the vignette parties. We require that each party be placed by at least 3 experts in order to be included in the estimation. With these restrictions, we are able to produce a cross-nationally comparable scale for the economic left-right, social left-right, and pro/anti-EU integration dimension for 249 parties based on the input of 337 experts. We estimated the model using JAGS via the R package rjags. For each dimension, we ran two chains for 20,000 iterations, discarding the first 5,000 as a burn-in. The chains show strong evidence of convergence across a variety of diagnostics.

After running the BAM procedure for each of the three dimensions for which we have vignette placements, we then sample 1,000 draws from the posterior distribution of each party's placement on each dimension. Figures 1 and 2 summarize these distributions graphically by plotting the mean and $95 \%$ credible interval of each party's distribution for the social dimension, separating the dimension into two graphs in order to make reading the y-axis labels easier. $^{2}$

\footnotetext{
${ }^{2}$ The party names and abbreviations in Figures 1 and 2 can be found online at chesdata.eu in the 2014 codebook. In Online Appendix B, Figures B1 and B2 plot the left-leaning and right-leaning parties in terms of economic positions while Figures B3 and B4 display the distributions of parties on the European dimension.
} 


\section{Party Placements with 95\% Credible Intervals}

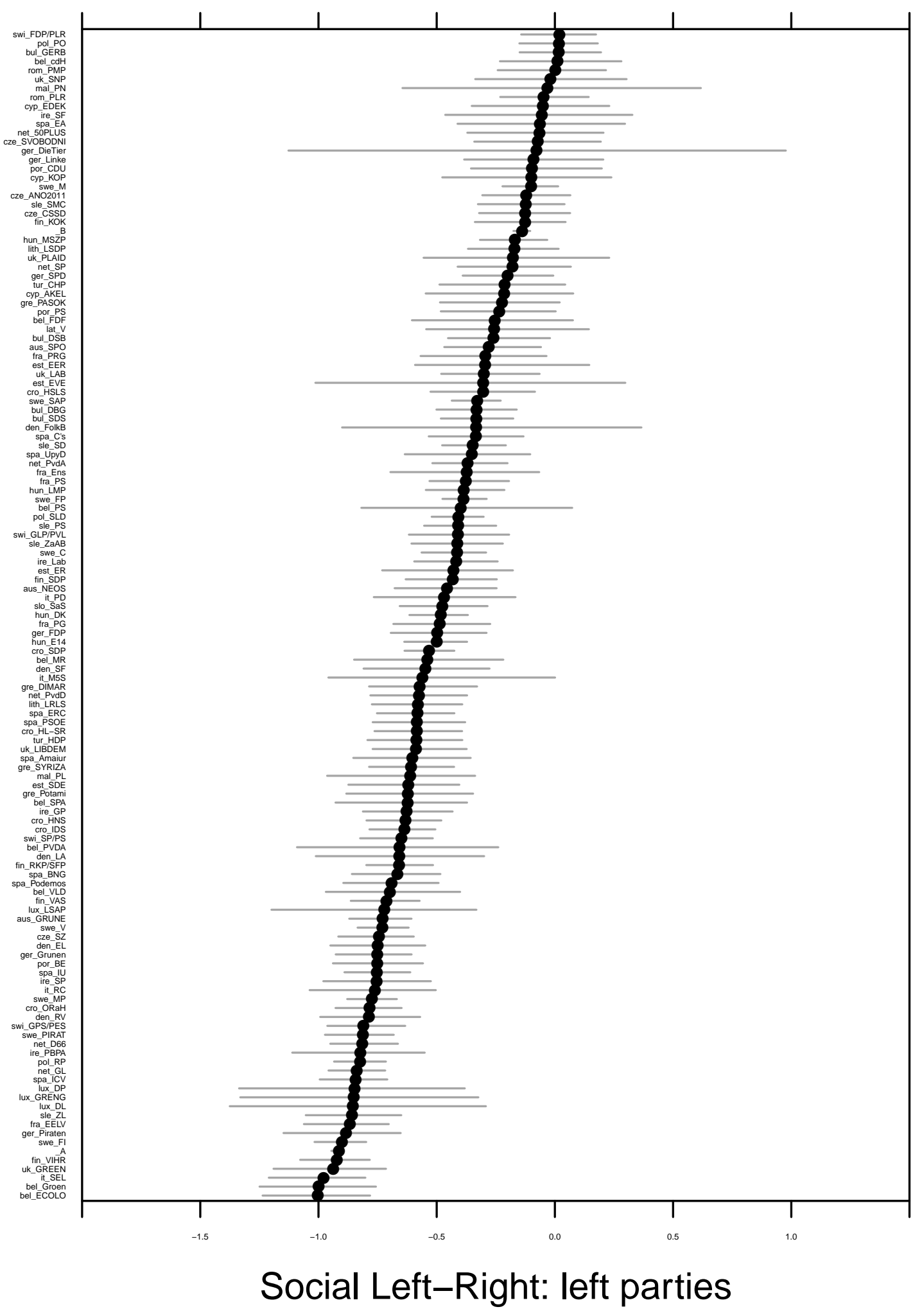

Figure 1: Social left-right 


\section{Party Placements with 95\% Credible Intervals}

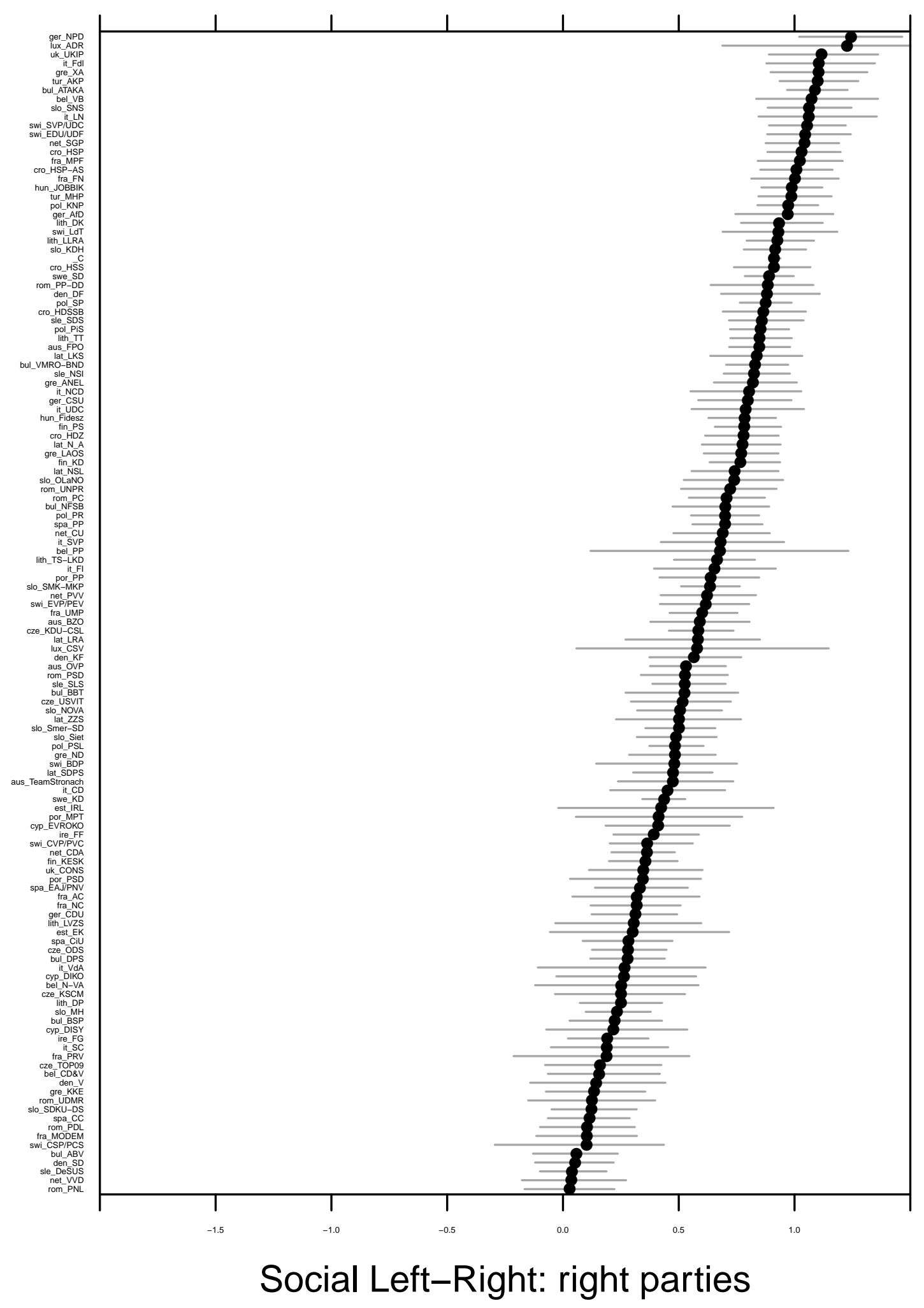

Figure 2: Social left-right 
As Figures 1-2 illustrate, there is a great deal of variation across these parties in terms of their positions on the social dimension. ${ }^{3}$ Yet, it is obviously important to examine the rescaled data more carefully and test their performance in analysis, to which we now turn.

\section{BAM vs. Raw}

What meaningful differences, if any, exist between the raw and adjusted data? The correlations between the raw and rescaled measures are very high, between 0.97 and 0.99 . But to explore this further, we sorted the data based on their rank orders on the two scales and plotted these against each other. Thus, we created 2 new variables for each dimension that range from 1 to 249 , representing the lowest to highest values on each dimension. Next, we plot these two sets of rank orders against each other. If there were no differences in the rank orders between the BAM solution and the unscaled expert placements, the points would fall in a straight 45 degree line. To the extent that the rank orders differ, the points diverge from the 'perfect' fit. Figure 3 displays these comparisons for the social dimension. ${ }^{4}$

\footnotetext{
${ }^{3}$ Parties with particularly large credible intervals tend to be those that were placed by smaller numbers of experts.

${ }^{4}$ Figures $\mathrm{C} 1$ and $\mathrm{C} 2$ in Online Appendix $\mathrm{C}$ display these comparisons for economic left-right and the European integration.
} 


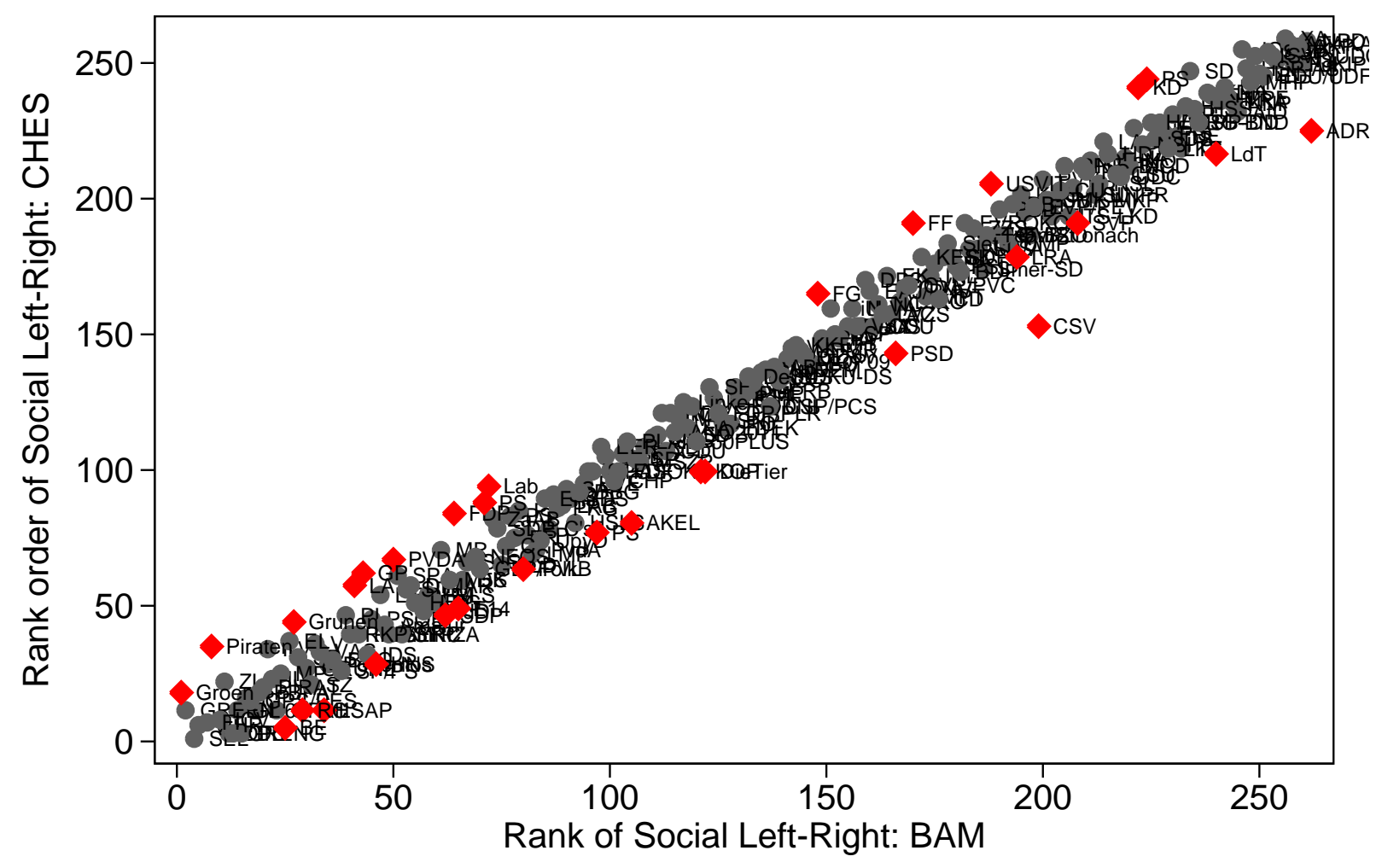

- Difference in rank $<2$ std dev $\diamond$ Difference in rank $>2$ std dev

Figure 3: Comparison of Social left-right rank orders 
In this plot, we highlight (with diamonds) parties that differ in rank ordering between the two scales by at least two standard deviations. These plots show that while there are some differences in the rank ordering of the parties across the two scales, for a majority of the parties in the data, these differences are not very large. It is particularly remarkable that the difference between the raw and adjusted data is so small for the social dimension, which contradicts our expectations given the complexity of this dimension relative to economic leftright and variation in its content from country to country. Yet, perhaps the small difference between the raw and rescaled social dimension reflects the growing importance of questions surrounding immigration, a core issue for this dimension in most if not all countries, and the clarity of party messages on migration.

As an additional test of the raw vs. rescaled measures, we replicated a prominent paper (Marks et al. 2006), which models support for European integration in 2002 using the economic and social dimensions. In online Appendix D, we used the rescaled dimensionality measures created in this paper to replicate and extend this earlier study of party-based Euroskepticism. This replication supports the key finding in that paper, namely that ideological extremism is still a crucial factor to consider. It is also striking that the raw and rescaled data perform rather similarly in these models, which lends confidence to users of the raw CHES scores.

\section{Discussion}

In this paper, we combined a series of anchoring vignettes that depicted hypothetical political parties with Bayesian scaling techniques to produce cross-nationally comparable economic left-right, social left-right, and European integration positions for a wide range of political parties in Europe. There was already growing theoretical and empirical evidence that the economic left-right dimension travelled well across Europe. The findings we report in this 
paper indicate that party positions on social left-right and European integration also show a strikingly high degree of pan-European comparability. That is, the Bayesian AldrichMcKelvey scaling solution produces a cross-contextually comparable measure and given that the raw expert party positions are so closely related to the rescaled party positions, we are ever more confident in the cross-national comparability of our experts placements. This is important information, both because these dimensions makes up an increasingly prominent aspect of party competition in Europe, and because it suggests that the items included in the Chapel Hill Expert Surveys measure these dimensions effectively. For users of the Chapel Hill Expert Survey data, these results provide more confidence in the cross-national comparability and validity of the CHES party positions.

Our replication of a well-known study on the relationship between economic and social ideology and European integration (Marks et al. 2006) further illustrates this point. Although the research we replicated used unscaled party positions from 2002, we find a similar structure to party positions on European integration in the 2014 raw and rescaled data. Party positions on European integration are structured and are systematically related to ideology on the economic and social left-right dimensions. In sum, the work that we present here supports the cross-national comparability of key concepts for party competition in contemporary European societies. 


\section{References}

Adams, James, Lawrence Ezrow, and Zeynep Somer-Topcu. 2014. "Do Voters Respond to Party Manifestos or to a Wider Information Environment? An Analysis of Mass-Elite Linkages on European Integration." American Journal of Political Science 58.4: 967-978.

Aldrich, John H. and Richard D. McKelvey. 1977. "A Method of Scaling with Applications to the 1968 and 1972 Presidential Elections." American Political Science Review 71.1 (March): 111-130.

Bakker, Ryan, Catherine De Vries, Erica Edwards, Liesbet Hooghe, Seth Jolly, Gary Marks, Jonathan Polk, Jan Rovny, Marco Steenbergen, and Milada Anna Vachudova. 2015. "Measuring party positions in Europe The Chapel Hill expert survey trend file, 1999-2010." Party Politics 21.1: 143-152.

Bakker, Ryan, Seth Jolly, Jonathan Polk, and Keith Poole. 2014. "The European Common Space: Extending the Use of Anchoring Vignettes." The Journal of Politics 76.4: 10891101.

Bechtel, Michael M, Jens Hainmueller, and Yotam Margalit. 2014. "Preferences for international redistribution: The divide over the Eurozone bailouts." American Journal of Political Science 58 (4): 835-856.

Benoit, Kenneth and Michael Laver. 2006. Party Policy in Modern Democracies. London: Routledge.

Böhmelt, Tobias, Lawrence Ezrow, Roni Lehrer, and Hugh Ward. 2016. "Party policy diffusion." American Political Science Review 110 (02): 397-410.

Bornschier, Simon. 2010. "The New Cultural Divide and the Two-Dimensional Political Space in Western Europe." West European Politics 33.3 (May): 419-444. 
Budge, Ian. 2000. "Expert Judgements of Party Policy Positions: Uses and Limitations in Political Research." European Journal of Political Research 37.1: 103-113.

Caramani, Daniele. 2017. "Will vs. reason: The populist and technocratic forms of political representation and their critique to party government." American Political Science Review $111(1): 54-67$.

Copelovitch, Mark, Jeffry Frieden, and Stefanie Walter. 2016. "The political economy of the Euro crisis." Comparative Political Studies 49 (7): 811-840.

de Vries, Catherine E. and Sara B Hobolt. 2012. "When Dimensions Collide: The Electoral Success of Issue Entrepreneurs." European Union Politics 13.2: 246-268.

Hare, Christopher, David A Armstrong, Ryan Bakker, Royce Carroll, and Keith T Poole. 2015. “Using Bayesian Aldrich-McKelvey Scaling to Study Citizens' Ideological Preferences and Perceptions." American Journal of Political Science 59 (3): 759-774.

Häusermann, Silja and Hanspeter Kriesi. 2015. "What Do Voters Want? Dimensions and Configurations in Individual-Level Preferences and Party Choice." In The Politics of Advanced Capitalism, ed. Pablo Beramendi, Silja Häusermann, Herbert Kitschelt, and Hanspeter Kriesi. Cambridge Polity Press.

Hobolt, Sara B. 2014. "A vote for the President? The role of Spitzenkandidaten in the 2014 European Parliament elections." Journal of European Public Policy 21 (10): 1528-1540.

Hobolt, Sara B. and James Tilley. 2016. "Fleeing the Centre: The Rise of Challenger Parties in the Aftermath of the Euro Crisis." West European Politics 39.5: 971-991.

Hobolt, Sara and Catherine de Vries. 2015. "Issue Entrepreneurship and Multiparty Competition." Comparative Political Studies 48.9: 1159-1185. 
Hooghe, Liesbet and Gary Marks. 2009. "A Postfunctionalist Theory of European Integration: From Permissive Consensus to Constraining Dissensus." British Journal of Political Science 39.1 (January): 1-23.

Hooghe, Liesbet, Ryan Bakker, Anna Brigevich, Catherine de Vries, Erica Edwards, Gary Marks, Jan Rovny, Marco Steenbergen, and Milada Vachudova. 2010. "Reliability and Validity of Measuring Party Positions: The Chapel Hill Expert Surveys of 2002 and 2006." European Journal of Political Research 49.5: 687-703.

Invernizzi-Accetti, Carlo and Fabio Wolkenstein. 2017. "The Crisis of Party Democracy, Cognitive Mobilization, and the Case for Making Parties More Deliberative." American Political Science Review 111 (1): 97-109.

King, Gary, Christopher J. L. Murray, Joshua A. Salmon, and Ajay Tandon. 2004. "Enhancing the Validity and Cross-Cultural Comparability of Measurement in Survey Research." American Political Science Review 98.1 (February): 191-207.

King, Gary and Jonathan Wand. 2007. "Comparing Incomparable Survey Responses: Evaluating and Selecting Anchoring Vignettes." Political Analysis 15.1: 46-66.

Kriesi, Hanspeter, Edgar Grande, Martin Dolezal, Marc Helbling, Dominic Höglinger, Swen Hutter, and Bruno Wüest. 2012. Political Conflict in Western Europe. Cambridge University Press.

Lindberg, Staffan I, Michael Coppedge, John Gerring, and Jan Teorell. 2014. "V-Dem: A new way to measure democracy." Journal of Democracy 25 (3): 159-169.

Marks, Gary, Liesbet Hooghe, Moira Nelson, and Erica Edwards. 2006. "Party Competition and European Integration in East and West. Different Structure, Same Causality." Comparative Political Studies 39 (March): 155-75. 
McDonald, Michael D., Silvia M. Mendes, and Myunghee Kim. 2007. "Cross-Temporal and Cross-National Comparisons of Party Left-Right Positions." Electoral Studies 26: 62-75.

McElroy, Gail and Kenneth Benoit. 2010. "Party Policy and Group Affilation in the European Parliament." British Journal of Political Science 40.2: 377-398.

Norris, Pippa, Richard W Frank, and Ferran Martínez i Coma. 2014. "Measuring Electoral Integrity around the World: A New Dataset." PS: Political Science 63 Politics 47 (04): 789-798.

Polk, Jonathan, Jan Rovny, Ryan Bakker, Erica Edwards, Liesbet Hooghe, Seth Jolly, Jelle Koedam, Filip Kostelka, Gary Marks, Gijs Schumacher, Marco Steenbergen, Milada Vachudova, and Marko Zilovic. 2017. "Explaining the salience of anti-elitism and reducing political corruption for political parties in Europe with the 2014 Chapel Hill Expert Survey data." Research $\mathcal{E}$ Politics 4.1 (January-March): 1-9.

Poole, Keith T. 1998. "Recovering a Basic Space From a Set of Issue Scales." American Journal of Political Science 42.3 (July): 954-993.

Popa, Sebastian Adrian, Robert Rohrschneider, and Hermann Schmitt. 2016. "Polarizing without legitimizing: The effect of lead candidates' campaigns on perceptions of the EU democracy." Electoral studies 44: 469-482.

Rohrschneider, Robert and Stephen Whitefield. 2012. The Strain of Representation: How Parties Represent Diverse Voters in Western and Eastern Europe. Oxford: Oxford University Press.

Rovny, Jan. 2014. "Communism, Federalism, and Ethnic Minorities: Explaining Party Competition Patterns in Eastern Europe." World Politics 66 (04): 669-708.

Schmitt, Hermann, Sara B. Hobolt, and Sebastian A. Popa. 2015. "Does personalization in- 
crease turnout? Spitzenkandidaten in the 2014 European Parliament elections." European Union Politics 16.3: 347-368.

Teorell, Jan, Carl Dahlström, and Stefan Dahlberg. 2011. "The QoG Expert Survey Dataset." University of Gothenburg: The Quality of Government Institute . 